\title{
EFEITO DA POROSIDADE DO SUBSTRATO CASCA DE PÍNUS NO DESENVOLVIMENTO DE MUDAS DE GRUMIXAMEIRA ${ }^{1}$
}

\author{
EDUARDO SUGUINO ${ }^{2}$, ADRIANA NOVAIS MARTINS $^{3}, \mathrm{KEIGO} \mathrm{MINAMI}^{4}$, \\ NOBUYOSHI NARITA ${ }^{5}$, MARCOS JOSÉ PERDONÁ 6
}

RESUMO - Objetivando-se avaliar o efeito da porosidade de substratos de casca de pínus no desenvolvimento de mudas de grumixameira (Eugenia brasiliensis Lam.), foi conduzido um experimento em casa de vegetação da Escola Superior de Agricultura "Luiz de Queiroz" - USP, Piracicaba-SP. Os tratamentos foram assim definidos: $100 \%$ casca de pínus moído sem separação de partículas; $100 \%$ casca de pínus $\leq 0,1$ $\mathrm{mm} ; 75 \%$ casca de pínus $\leq 0,1 \mathrm{~mm}+25 \%$ entre $0,1-4,0 \mathrm{~mm} ; 50 \%$ casca de pínus $\leq 0,1 \mathrm{~mm}+50 \%$ entre $0,1-4,0 \mathrm{~mm} ; 25 \%$ casca de pínus $\leq 0,1 \mathrm{~mm}+75 \%$ entre $0,1-4,0 \mathrm{~mm}$, e $100 \%$ casca de pínus $0,1-0,4 \mathrm{~mm}$. As avaliações (diâmetro do caule, comprimento total e média de massa seca das plântulas) ocorreram aos 90; 120 e 150 dias após a semeadura. A baixa absorção de água nos estágios iniciais e a baixa aeração das raízes, promovida pelo substrato afetam o desenvolvimento de mudas de grumixameira, que se desenvolve melhor quando o espaço poroso total do substrato é inferior a $90 \%(\mathrm{v} / \mathrm{v})$.

Termos para indexação: produção de mudas; espaço poroso; Eugenia brasiliensis; grumixama; plantas nativas.

\section{EFFECT OF PINUS BARK SUBSTRATE POROSITY IN THE DEVELOPMENT OF GRUMIXAMA PLANT SEEDLINGS}

\begin{abstract}
Aiming to evaluate the effect of the pine bark substrate porosity on the development of the grumixama plant (Eugenia brasiliensis Lam.), an experiment was conducted in a greenhouse of the Escola Superior de Agricultura "Luiz de Queiroz"/USP, Piracicaba, Brazil. The treatments were: 100\% ground pine bark without separation of particles; $100 \%$ pine bark of $\leq 0,1 \mathrm{~mm} ; 75 \%$ pine bark of $\leq 0,1 \mathrm{~mm}+25 \%$ between $0,1-4,0 \mathrm{~mm} ; 50 \%$ of pine bark $\leq 0,1 \mathrm{~mm}+50 \%$ between $0,1-4,0 \mathrm{~mm} ; 25 \%$ pine bark of $\leq 0,1 \mathrm{~mm}$ $+75 \%$ between $0,1-4,0 \mathrm{~mm}$ and $100 \%$ pine bark of $0,1-4,0 \mathrm{~mm}$. The evaluations (stem diameter, length and average dry weight of seedlings) were performed on the 90,120 and $150^{\text {th }}$ days after sowing. The low water absorption in the early stages and the low aeration of the roots promoted by the substrate, affect the development of the grumixama plant seedlings, that grow best when the total pore space of the substrate is less than $90 \%(\mathrm{v} / \mathrm{v})$.
\end{abstract}

Index terms: seedling production; porous space; Eugenia brasiliensis; grumixama; native plants.

\section{INTRODUÇÃO}

A grumixameira é o nome popular da Eugenia brasiliensis Lam., com sinonímias como Stenocalyx brasiliensis Berg., E. bracteolaris Lam., E. Dombeyi Skeels, dentre outras. Também é conhecida como grumichama, cumbixaba e ibaporoiti, no Brasil, e
Brazil-cherry nos países de língua inglesa. É uma mirtácea nativa e muito encontrada na região Sudeste do Brasil. É uma árvore de porte médio que produz frutos do tipo baga, com duas colorações básicas, que são o amarelo e o roxo-escuro ou preto, como é comumente conhecido.

É propagada basicamente por sementes, sendo

\footnotetext{
${ }^{1}$ Trabalho Sinfruit 129 - Simpósio Internacional de Fruticultura - Avanços na Fruticultura (17 a 21 Outubro)

${ }^{2}$ APTA/SAA. Polo Centro Leste, Av. Bandeirantes, 2419, CEP 14030-670. Ribeirão Preto - São Paulo, Brasil. *autor para correspondência: esuguino@apta.sp.gov.br. Bolsista Capes.

${ }^{3}$ Doutora em Agronomia, Pesquisador Científico da APTA/SAA. Polo Centro Oeste/UPD Marília, Rua Andrade Neves, 81, CEP 17515-400. Marília - São Paulo, Brasil. Email: adrianamartins@apta.sp.gov.br

${ }^{4}$ Doutor em Agronomia, Professor da ESALQ/USP - Av. Pádua Dias, 11 - Piracicaba - SP. Email: kminami@esalq.usp.br

${ }^{5}$ Doutor em Agronomia, Pesquisador Científico da APTA/SAA. Polo Alta Sorocabana, Rod. Raposo Tavares km 561, CEP 19015-970. Presidente Prudente - São Paulo, Brasil. Email: narita@apta.sp.gov.br

${ }^{6}$ Doutorando em Agronomia pela UNESP - Botucatu-SP, Pesquisador Científico da APTA/SAA. Pólo Centro Leste, Av. Bandeirantes, 2419,
} 
os frutos formados a partir do quinto ano. Floresce entre os meses de novembro e fevereiro e possui frutos maduros, em geral, um mês após a abertura das flores. A taxa de germinação da grumixameira, geralmente baixa, pode ser observada 30 a 60 dias após a semeadura, que corresponde ao início do período de emergência das plântulas (SUGUINO et al., 2006).

A polpa tem sabor doce-acidulado, muito apreciado e utilizado para fazer doces, xaropes, licores e geleias. No caso da sua utilização como planta medicinal, existem referências do seu uso como antidisentérico e até mesmo em casos de reumatismo (FISCHER et al., 2003).

Segundo Lorenzi et al. (2006), as frutíferas nativas paulistas, com poucas citações na literatura e pouco conhecidas pela população brasileira, são alimentos de grande potencial de exploração comercial, pois apesar do seu consumo ocorrer principalmente in natura, podem ser utilizadas como fonte de nutrientes, extração de compostos químicos para fins industriais, gastronômicos ou apenas para ornamentar uma mesa ou prato.

Os frutos da grumixameira fazem parte do grupo de frutas de polpa carnuda e suculenta que apresentam baixo valor calórico (LORENZI et al., 2006), ideais para alguns tipos de dieta, criando admiração e simpatia entre os que buscam a saúde vinda da natureza.

Dia após dia, mais médicos e nutricionistas unem-se para comentar e chamar a atenção das pessoas para a importância do valor nutracêutico das frutas incorporadas na alimentação, uma vez que estas auxiliam no bom funcionamento do aparelho digestivo, previnem um grande número de doenças, além disso há enorme quantidade de vitaminas e seus precursores (LORENZI et al., 2006), que as tornam um alimento sinônimo de uma vida saudável.

A formação de mudas de espécies nativas, cuja literatura é escassa, é principalmente realizada por meio de sementes, método que gera muita variabilidade, afetando a qualidade do material produzido, podendo interferir diretamente na longevidade do pomar e no vigor das plantas, uma vez que, em termos de fisiologia vegetal, as mudas, quando mal formadas, só trazem prejuízos aos produtores (GENTIL; MINAMI, 2005).

Para o sucesso na multiplicação destas espécies, um substrato com boas características de uniformidade, facilidade de manuseio, boa capacidade de retenção de água, aeração e drenagem é fundamental para a produção de mudas de alta qualidade, pois é ele quem possibilita boa formação de raízes (KÄMPF, 2000), facilitando o pegamento e o desenvolvimen- tos no campo.

Num substrato, são considerados macroporos os espaços nos quais, logo após a saída da água da livre drenagem, enchem-se de ar, e os mesoporos são aqueles em que a água fica disponível quando a tensão é de $100 \mathrm{hPa}$, nos casos em que a disponibilidade hídrica em tensões iguais ou superiores a esta, os poros recebem a denominação de microporos (DAUDT et al., 2007)

Apesar de ser uma espécie com importância para reflorestamento e e possíveis propriedades medicinais, são raros os estudos realizados com esta fruteira; desta maneira, este trabalho foi executado com o objetivo de avaliar a influência do substrato no desenvolvimento de mudas de grumixama.

\section{MATERIAL E MÉTODOS}

O experimento foi conduzido na estufa do Departamento de Produção Vegetal da Escola Superior de Agricultura "Luiz de Queiroz" - Universidade de São Paulo (ESALQ/USP) em Piracicaba - SP. As sementes utilizadas, foram retiradas dos frutos maduros, colhidos de plantas adultas encontradas na área experimental da ESALQ.

A fim de se evitar que nas 24 horas decorridas entre a extração das sementes e a semeadura, estas sofressem algum dano significativo que comprometesse a germinação, as sementes, logo após a retirada, remoção da mucilagem e seleção, foram secas à sombra, com temperatura em torno de $25^{\circ} \mathrm{C}$, até a eliminação da água superficial (LORENZI; MATOS, 2002) e, em seguida, foram acondicionadas em embalagens plásticas, fechadas e mantidas em ambiente refrigerado, evitando assim a perda de umidade.

As sementes foram colocadas para germinar em bandejas de poliestireno expandido, com 72 células, em estufas com nebulização intermitente. Oliveira et al. (1993), trabalhando com plantas frutíferas, verificaram que este tamanho de bandeja foi o que mostrou os melhores resultados no que se refere ao desenvolvimento do sistema radicular das mudas, independentemente do tipo de matéria-prima utilizada como substrato.

O delineamento estatístico utilizado foi o esquema em blocos inteiramente casualizado com medidas repetidas no tempo, sendo 6 tratamentos, 5 repetições e 12 plantas em cada unidade experimental. . Os valores do espaço poroso total (EPT) foram definidos segundo a metodologia de Smith e Pokorny (1977) e encontram-se na Tabela 1.

Os tratamentos foram definidos da seguinte maneira: $\mathrm{T} 1(\mathrm{EPT}=83,9 \%)=100 \%$ material original ((casca de pínus moído sem separação de partículas); 
$\mathrm{T} 2(\mathrm{EPT}=96,8 \%)=100 \%$ casca de pínus $\leq 0,1 \mathrm{~mm}$ (partículas pequenas); T3 $(\mathrm{EPT}=92,3 \%)=75 \%$ casca de pínus $\leq 0,1 \mathrm{~mm}+25 \%$ casca de pínus 0,1 - 4,0mm; T4 $(\mathrm{EPT}=86,4 \%)=50 \%$ casca de pínus $\leq 0,1 \mathrm{~mm}+50 \%$ casca de pínus $0,1-4,0 \mathrm{~mm}$; T5 (EPT $=80,4 \%)=25 \%$ casca de pínus $\leq 0,1 \mathrm{~mm}+75 \%$ casca de pínus 0,1 - 4,0mm; T6 $(\mathrm{EPT}=77,4 \%)=100 \%$ casca de pínus $0,1-0,4 \mathrm{~mm}$ (partículas grandes).

As avaliações tiveram início 90 dias após a instalação do experimento (semeadura). Este tempo foi definido em função do fato de que espécies de frutíferas da família Myrtaceae, como a grumixama, demoram de 30 a 60 dias para germinar (SUGUINO et al., 2006), e mais 30 dias foram concedidos de maneira que a plântula pudesse desenvolver-se um pouco mais, antes da primeira avaliação.

Verificada a emergência das plântulas, elas foram separadas em três grupos com o mesmo número de plantas cada, de maneira que o grupo formado fosse homogêneo dentro da unidade experimental. Das plantas de cada grupo, em cada mês de avaliação, foram anotados o comprimento total (parte aérea e parte radicular) e o diâmetro do caule. Isto feito, elas foram colocadas em estufas de secagem a $70^{\circ} \mathrm{C}$ por 72 horas, quando foi anotada a massa seca dos caules, das folhas e das raízes. As análises estatísticas dos dados foram analisadas pelo procedimento GLM (SAS, 2003), e as comparações entre os tratamentos foram realizadas pelo teste de Tukey, com probabilidade de $5 \%$.

\section{RESULTADOS E DISCUSSÃO}

Não houve diferença significativa na formação das mudas nos substratos dos tratamentos $1 ; 3$; 4; 5 e 6 , nas avaliações temporais de massa seca, de folhas, caules e raízes, nas médias das 3 avaliações que ocorreram aos 90; 120 e 150 dias, mostrando que houve uniformidade nestas formulações quanto às características exigidas pela planta, para o seu desenvolvimento (Tabelas 2 e 3 ). Quando o substrato fornece condições para que a muda formada seja de qualidade, com a parte aérea e as raízes bem desenvolvidas, permitirá que a mesma tenha um rápido pegamento no transplante e possa suportar melhor as condições adversas no ambiente que possam vir a surgir (ECHER et al., 2007).

A relação ar-água de alguns substratos comerciais formulados com casca de pínus, com porosidade total de $79 \%$, espaço de aeração $22 \%$ e granulometria com $70,62 \%$ das partículas de tamanho entre 0,50 e $4,75 \mathrm{~mm}$, indicam que este poderia ser utilizado como meio de suporte para cultivo (VALERO et al., 2009). Essas propriedades físicas possuem valores muito semelhantes aos da mistura utilizada no tratamento 5 .

Segundo Wall e Heiskanen (2009), a alta quantidade de água do meio de cultivo orgânico, como a casca de pínus, associado ao pequeno volume de ar disponível limitam a aeração do meio, o que prejudica o crescimento da planta. Essa observação concorda com os resultados obtidos neste experimento, no que se refere ao tratamento 2 , onde houve maior quantidade de partículas finas no substrato, e os espaços preenchidos com água, neste substrato, foram superiores a $80 \%$, e o valor do EPT foi superior a $95 \%$, provocando falta de aeração nas raízes, prejudicando a germinação e o desenvolvimento das mudas de grumixama.

Formulações de substrato que diminuem a macroporosidade do meio de cultivo criam condições desfavoráveis para a germinação das sementes, o estabelecimento e o crescimento das mudas germinadas, pois, ao aumentar o número de microporos, diminui-se a aeração no interior do substrato, o que pode explicar o ocorrido na mistura final do tratamento 2, cujos dados são informados nas Tabelas 2 e 3 ( BLOUIN et al., 2008).

Este fato corrobora, também, as observações feitas por Ansorena Miner (1994) de que o aumento na quantidade de água retida é maior em substratos com muitas partículas pequenas (até $1,0 \mathrm{~mm}$ ), pois isso diminui a porosidade total, promovendo o aumento do número de microporos, que são responsáveis pela retenção da água, mostrando a importância da distribuição das partículas de diferentes tamanhos do substrato.

Outro fator que pode explicar o ocorrido no tratamento 2, é que o crescimento das mudas de grumixama é lento (SUGUINO et al., 2006), e por cauda disso, os microporos formados no substrato mantiveram a água deste mais fortemente aderida, dificultando a entrada do ar, reduzindo a oxigenação em torno das sementes ou raízes, prejudicando o processo germinativo e também a sobrevivência das plântulas ( LUDWIG et al., 2008).

Essas observações estabelecem outra provável causa para a baixa germinação das sementes de grumixama no substrato do tratamento 2 , também ser explicadas por Sodré et al. (2007) em trabalho realizado com mudas de cacaueiro, em que foi observado que durante o cultivo, as atividades relacionadas ao transporte das bandejas e acomodação do substrato no recipiente alteraram os valores de espaço poroso total, provocando um desequilíbrio na proporção de macro e microporos, o qual alterou as propriedades físicas do meio, o que dificultar a germinação e a sobrevivência das mudas. 
Referindo-nos ainda às observações sobre o tratamento 2, verifica-se que estas discordam das relatadas por Lopes et al. (2008), em que, o EPT dos substratos utilizados, cujos valores foram de $75,52 \%$ e $76,50 \%$, eram baixos em relação ao nível ótimo acima de $85 \%$ por eles considerados, visto que no tratamento 2 o EPT de $95 \%$, apesar de superior ao considerado pelos autores, foi prejudicial para as plântulas germinadas que devido as condições do meio, morreram, dessa forma o programa estatístico analisou as informações obtidas, e considerou os dados como não estimáveis (Tabelas 2 e 3 ).

Wendling et al. (2007), em experimentos com mudas de erva-mate (Ilex paraguariensis St. Hil.), verificaram que a taxa de mortalidade foi maior em substrato de casca de pínus com EPT de 74,5\%, e que possuía a maior quantidade de microporos quando comparado aos outros substratos. Para a grumixameira, apenas onde o valor de EPT foi superior a 95\% é que as taxas de mortalidade foram elevadas.

Segundo Ribeiro et al. (2007), a distribuição dos poros na matriz do meio de cultivo desempenha um papel fundamental nas relações entre as fases sólida, líquida e gasosa, determinando a evolução espacial e temporal dos processos que envolvem o movimento hídrico. Desse modo, o comportamento físico- hídrico que define a potencialidade agrícola do meio, fica condicionado à distribuição dos poros e à variação dos seus tamanhos. Esse equilíbrio foi conseguido nos tratamentos $1 ; 3 ; 4 ; 5$ e 6 , onde o desenvolvimento das mudas foi satisfatório, não apresentando diferenças significativas entre essas formulações de substrato.

As sementes de espécies pertencentes à família Myrtaceae são recalcitrantes, ou seja, não toleram a perda de água, sofrendo danos significativos, principalmente nos períodos de armazenamento ( JUSTO et al., 2007). Assim sendo, essas sementes perdem rapidamente o poder germinativo quando expostas às condições de baixa umidade (DELGADO;BARBEDO, 2007). No entanto, a existência de material vegetal, nos tratamentos $1 ; 3$; 4; 5 e 6 até a avaliação dos 150 dias, mostrou que o lote de sementes selecionadas era viável (Tabelas 2 e 3).

Em seu trabalho com a produção de mudas de gérbera em vaso, Ludwig et al. (2010) relatam que os substratos com $30 \%$ de casca de pínus em sua composição e porosidade total de $89,18 \%$ foram adequados para a maioria das culturas, proporcionando o melhor desenvolvimento das plantas. Essa mesma observação foi constatada neste experimento, nos tratamentos $1 ; 3 ; 4 ; 5$ e 6 , cujos valores de EPT para estes substratos foram inferiores a $92,3 \%$ e, portanto próximos ao relatado pelos autores. No caso específico da grumixama, as mudas apresentaram dificuldade para se desenvolver apenas em substratos com ETP de $96,8 \%$, pois os demais tratamentos não apresentaram diferenças significativas entre si.

TABELA 1 - Análise de várias misturas e proporções do substrato casca de pínus

\begin{tabular}{cccccccc}
\hline Mistura & $\begin{array}{c}\mathrm{O} \\
\%\end{array}$ & $\begin{array}{c}\mathrm{P} \\
\%\end{array}$ & $\begin{array}{c}\mathrm{G} \\
\%\end{array}$ & $\begin{array}{c}\mathrm{DA} \\
\left(\mathrm{g} . \mathrm{cm}^{-3}\right)\end{array}$ & $\begin{array}{c}\text { PA10 } \\
\%(\mathrm{v} / \mathrm{v})\end{array}$ & $\begin{array}{c}\text { EPA10 } \\
\%(\mathrm{v} / \mathrm{v})\end{array}$ & $\begin{array}{c}\text { EPT } \\
\%(\mathrm{v} / \mathrm{v})\end{array}$ \\
\hline T1 & 100 & 0 & 0 & 0,5 & 14,0 & 69,9 & 83,8 \\
T2 & 0 & 100 & 0 & 0,6 & 14,7 & 82,1 & 96,8 \\
T3 & 0 & 75 & 25 & 0,5 & 12,9 & 79,4 & 92,3 \\
T4 & 0 & 50 & 50 & 0,5 & 15,9 & 70,5 & 86,4 \\
T5 & 0 & 25 & 75 & 0,4 & 22,7 & 57,7 & 80,4 \\
T6 & 0 & 0 & 100 & 0,4 & 15,0 & 62,4 & 77,4 \\
\hline
\end{tabular}

Legenda:

$\mathrm{O}=$ material original;

$\mathrm{P}=$ material fino, partículas pequenas (com tamanho $\leq 0,1 \mathrm{~mm}$ );

$\mathrm{G}=$ material grosso, partículas grandes (com tamanho entre $0,1-4,0 \mathrm{~mm}$ );

$\mathrm{DA}=$ densidade aparente;

$\mathrm{PA}=$ porosidade de aeração;

EPA = espaço preenchido com água;

$\mathrm{EPT}=$ espaço poroso total;

$10=$ altura da coluna de água na mesa de tensão em $\mathrm{cm}$.

T1 - 100\% material original (casca de pinus moído sem separação de partículas) (EPT = 83,9\%); T2 - 100\% casca de pinus $\leq 0,1$ mm (partículas pequenas) $(\mathrm{EPT}=96,8 \%) ; \mathrm{T} 3-75 \%$ casca de pinus $\leq 0,1 \mathrm{~mm}+25 \%$ casca de pinus $0,1-4,0 \mathrm{~mm}(\mathrm{EPT}=92,3 \%) ; \mathrm{T} 4-50 \%$ casca de pinus $\leq 0,1 \mathrm{~mm}+50 \%$ casca de pinus $0,1-4,0 \mathrm{~mm}(\mathrm{EPT}=86,4 \%)$; $55-25 \%$ casca de pinus $\leq 0,1 \mathrm{~mm}+75 \%$ casca de pinus 0,1 - 4,0 $\mathrm{mm}(\mathrm{EPT}=80,4 \%) ; \mathrm{T} 6-100 \%$ casca de pinus $0,1-0,4 \mathrm{~mm}$ (partículas grandes) $(\mathrm{EPT}=77,4 \%)$. 
TABELA 2 - Diâmetro do caule e altura total das mudas de grumixama.

\begin{tabular}{lcccccc}
\hline \multirow{2}{*}{ Tratamentos } & \multicolumn{3}{c}{ Diâmetro do caule $(\mathbf{m m})$} & \multicolumn{3}{c}{ Altura total $(\mathbf{c m})$} \\
\cline { 2 - 7 } & 90dias & $\mathbf{1 2 0 d i a s}$ & $\mathbf{1 5 0 d i a s}$ & $\mathbf{9 0 d i a s}$ & 120dias & 150dias \\
\hline $\mathrm{T} 1-100 \%$ material original & $1,33 \mathrm{a}$ & $1,89 \mathrm{a}$ & $2,33 \mathrm{a}$ & $18,70 \mathrm{a}$ & $20,64 \mathrm{a}$ & $22,45 \mathrm{a}$ \\
$\mathrm{T} 2-100 \%$ casca pínus $\leq 0,1 \mathrm{~mm}$ & $\mathrm{DNE}$ & $\mathrm{DNE}$ & $\mathrm{DNE}$ & $\mathrm{DNE}$ & $\mathrm{DNE}$ & $\mathrm{DNE}$ \\
$\mathrm{T} 3-75 \%(\leq 0,1 \mathrm{~mm})+25 \%(0,1-4,0 \mathrm{~mm})$ & $1,36 \mathrm{a}$ & $\mathrm{DNE}$ & $2,13 \mathrm{a}$ & $18,65 \mathrm{a}$ & $\mathrm{DNE}$ & $22,02 \mathrm{a}$ \\
$\mathrm{T} 4-50 \%(\leq 0,1 \mathrm{~mm})+50 \%(0,1-4,0 \mathrm{~mm})$ & $1,31 \mathrm{a}$ & $1,78 \mathrm{a}$ & $2,16 \mathrm{a}$ & $18,47 \mathrm{a}$ & $20,14 \mathrm{a}$ & $21,86 \mathrm{a}$ \\
$\mathrm{T} 5-25 \%(\leq 0,1 \mathrm{~mm})+75 \%(0,1-4,0 \mathrm{~mm})$ & $1,39 \mathrm{a}$ & $1,72 \mathrm{a}$ & $2,18 \mathrm{a}$ & $18,51 \mathrm{a}$ & $20,18 \mathrm{a}$ & $21,96 \mathrm{a}$ \\
$\mathrm{T} 6-100 \%$ casca pínus $(0,1-0,4 \mathrm{~mm})$ & $1,33 \mathrm{a}$ & $1,67 \mathrm{a}$ & $2,09 \mathrm{a}$ & $18,49 \mathrm{a}$ & $20,35 \mathrm{a}$ & $21,54 \mathrm{a}$ \\
\multicolumn{1}{c}{ CV\% } & 17,69 & 18,02 & 12,34 & 8,74 & 12,27 & 8,42 \\
\hline
\end{tabular}

DNE = Dados Não Estimáveis (devido ao pequeno número de plantas que puderam ser avaliadas neste tratamento, o programa estatístico não conseguiu analisá-lo). Médias ajustadas pelo método dos quadrados mínimos, das três avaliações referentes ao diâmetro do caule e altura total das mudas de grumixama. Médias seguidas pela mesma letra, na coluna, não diferem entre si, pelo teste de Tukey, a $5 \%$ de probabilidade.

TABELA 3 - Média da massa seca das folhas, caules e raízes de grumixama.

\begin{tabular}{|c|c|c|c|}
\hline \multirow[t]{2}{*}{ Tratamentos } & \multicolumn{3}{|c|}{ Média da Massa Seca (gramas) } \\
\hline & Folhas & Caules & Raízes \\
\hline T1 - 100\% material original & $0,30 \mathrm{a}$ & $0,13 \mathrm{a}$ & $0,12 \mathrm{a}$ \\
\hline $\mathrm{T} 2$ - $100 \%$ casca de pínus $\leq 0,1 \mathrm{~mm}$ (partículas pequenas) & DNE & DNE & DNE \\
\hline T3 - $75 \%$ casca pínus $\leq 0,1 \mathrm{~mm}+25 \%$ casca pínus $0,1-4,0 \mathrm{~mm}$ & $0,22 \mathrm{a}$ & $0,10 \mathrm{a}$ & $0,09 \mathrm{a}$ \\
\hline $\mathrm{T} 4-50 \%$ casca pínus $\leq 0,1 \mathrm{~mm}+50 \%$ casca pínus $0,1-4,0 \mathrm{~mm}$ & $0,24 \mathrm{a}$ & $0,11 \mathrm{a}$ & $0,09 \mathrm{a}$ \\
\hline T5 - $25 \%$ casca pínus $\leq 0,1 \mathrm{~mm}+75 \%$ casca pínus $0,1-4,0 \mathrm{~mm}$ & $0,24 \mathrm{a}$ & $0,10 \mathrm{a}$ & $0,11 \mathrm{a}$ \\
\hline T6 - 100\% casca de pínus $0,1-0,4 \mathrm{~mm}$ (partículas grandes) & $0,24 \mathrm{a}$ & $0,10 \mathrm{a}$ & $0,10 \mathrm{a}$ \\
\hline $\mathrm{CV} \%$ & 32,30 & 21,63 & 23,08 \\
\hline
\end{tabular}

DNE = Dados Não Estimáveis (devido ao pequeno número de plantas que puderam ser avaliadas neste tratamento, o programa estatístico não conseguiu analisá-lo).

Valores médios das três avaliações referentes à massa seca das folhas, caules e raízes das mudas de grumixama.

Médias seguidas pela mesma letra, na coluna, não diferem entre si, pelo teste de Tukey, a 5\% de probabilidade.

\section{CONCLUSÕES}

1. A baixa aeração do substrato influencia negativamente o desenvolvimento de mudas de grumixameira;

2. Substrato com baixa absorção de água nos estágios iniciais prejudica a germinação das sementes de grumixama.

3. O desenvolvimento das mudas de grumixameira foi beneficiado nos tratamentos onde o substrato utilizado apresentou espaço poroso total abaixo dos $90 \%(\mathrm{v} / \mathrm{v})$.

\section{AGRADECIMENTOS}

À Capes, pelo auxílio financeiro conferido ao primeiro autor.

\section{REFERÊNCIAS}

ANSORENA MINER, J. Substratos: propriedades y caracterizacion. Madrid: Mundi-Prensa, 1994. 172 p.
BLOUIN, V.M.; SCHMIDT, M.G.; BULMER, C.E.; KRZIC, M. Effects of compaction and water content on lodgepole pine seedling growth. Forest Ecology and Management, Amsterdam , v. 255, n. 7, p. 2444-2452, 2008.

DAUDT, R.H.S.; GRUSZYNSKI, C.; KÄMPF, A.N. Uso de resíduos de couro wet-blue como componente de substrato para plantas. Ciência Rural, Santa Maria, v. 37, n. 1, p. 91-96, 2007.

DELGADO, L.F.; BARBEDO, C.J. Tolerância à dessecação de sementes de espécies de Eugenia. Pesquisa Agropecuária Brasileira, Brasília, v. 42, n. 2, p. 265-272, 2007.

ECHER, M.M. ; GUIMARÃES, V.F. ; ARANDA, A.N. ; BORTOLAZZO, E.D. ; BRAGA, J.S. Avaliação de mudas de beterrabaem função do substrato e do tipo de bandeja. Semina: Ciências Agrárias, Londrina, v. 28, n. 1, p. 45-50, 2007. 
FISCHER, D.C.H.; KATO, E.T.M.; KONISHI, S.T. Pharmacognostic characterization of leaves and stem barks of Eugenia brasiliensis LAM. (Myrtaceae). Revista Brasileira de Plantas Medicinais, Botucatu, v. 6, n. 1, p. 15-22, 2003.

GENTIL, D.F.O.; MINAMI, K. Uvaieira, pitangueira e jabuticabeira: cultivo e utilização. Piracicaba: FEALQ, 2005.

JUSTO, C.F.; ALVARENGA, A.A.; ALVES, E; GUIMARÃES, R.M.; STRASSBURG, R.C. Efeito da secagem, do armazenamento e da germinação sobre a micromorfologia de sementes de Eugenia pyriformis Camb. Acta Botanica Brasilica, São Paulo, v. 21, n. 3, p.539-551, 2007.

KÄMPF, A.N. Seleção de materiais para uso como substrato. In: KÄMPF, A.N.; FERMINO, M.H. (Ed.). Substrato para plantas: base da produção vegetal em recipientes. Porto Alegre: Genesis, 2000. p.139-146.

LOPES, J.L.W.; GUERRINI, I.A.; SAAD, J.C.C.; SILVA, M.R.da. Atributos químicos e físicos de dois substratos para a produção de mudas de eucalipto. Cerne, Lavras, v. 14, n. 4, p. 358-367, 2008.

LORENZI, H.; MATOS, F.J.A. Plantas medicinais do Brasil: nativas e exóticas cultivadas. Nova Odessa: Instituto Plantarum, 2002.

LORENZI, H; BACHER, L.B.; LACERDA, M.; SARTORI, S. Frutas brasileiras e exóticas cultivadas: (de consumo in natura). Nova Odessa: Instituto Plantarum de Estudos da Flora, 2006.

LUDWIG, F.; FERNANDES, D.M.; SANCHES, L.V.C.; BOAS, R.L.V. Caracterização física de substratos formulados a partir de casca de pinus e terra vermelha. In: ENCONTRO NACIONAL DE SUSBTRATOS PARA PLANTAS - MATERIAIS REGIONAIS PARA SUSBTRATOS, 6., 2008, Fortaleza. Anais... Fortaleza: UFC, 2008.

LUDWIG, F.; GUERRERO, A.C.; FERNANDES, D.M.; BOAS, R.L.V. Análise de crescimento de gérbera de vaso conduzida em diferentes substratos. Horticultura Brasileira, Brasília, v. 28, n. 1, p. 70-74, 2010.

MOTA, J.C.A.; ASSIS JÚNIOR, R.N.de; AMARO FILHO, J.; LIBARDI, P.L. Algumas propriedades físicas e hídricas de três solos da chapada do Apodi, RN, cultivadas com melão. Revista Brasileira de Ciência do Solo, Viçosa, MG, v.32, f.1, p. 49-58, 2008.
OLIVEIRA, R.P.; SCIVITTARO, W.B.; VASCONCELLOS, L.A.B.C. Avaliação de mudas de maracujazeiro em função do substrato e tipo de bandeja. Scientia Agricola, Piracicaba, v. 50, n. 2, p. 261-266, 1993.

RIBEIRO, K.D.; MENEZES, S.M.; MESQUITA, M.G.B.F.; SAMPAIO, F.M.T. Propriedades físicas do solo, influenciadas pela distribuição de poros, de seis classes de solos da região de Lavras-MG. Ciência e Agrotecnologia, Lavras, v. 31, n. 4, p. 1167-1175, 2007.

SMITH, R.C.; POKORNY, F.A. Physical characterization of some potting substrates used in commercial nurseries. SNA Nursery Research Journal, Nashville, v.4, p.1-8, 1977.

SODRÉ, G.A.; CORÁ, J.E.; SOUZA JÚNIOR, J.O. Caracterização física de substratos à base de serragem e recipientes para crescimento de mudas de cacaueiro. Revista Brasileira de Fruticultura, Jaboticabal, v. 29, n. 2, p.339-344, 2007.

SUGUINO, E.; HEIFFIG, L.S.; SAAVEDRA del AGUILA, J.; MINAMI, K. Mirtáceas com frutos comestíveis do estado de São Paulo: conhecendo algumas plantas. Piracicaba: ESALQ, Divisão de Biblioteca e Documentação, 2006. 56 p. (Série Produtor Rural, 31).

SAS INSTITUTE. SAS/STAT 2003: user's guide: statistics version 9.1. Cary, 2003. 1 CD-ROM.

VALERO, R.M.M.; MATSURA, E.E.; SOUZA, A.L. de. Caracterização física de dois substratos orgânicos para plantas e a estimativa de umidade por meio da reflectometria no domínio do tempo. Ciência Rural, Santa Maria, v. 39, n. 2, p. 571-574, 2009.

WALL, A.; HEISKANEN, J. Soil-water content and air-filled porosity affect height growth of Scots pine in afforested arable land in Finland. Forest Ecology and Management, Amsterdam, v. 257, n. 8, p. 1751-1756, 2009.

WENDLING, I.; GUASTALA, D.; DEDECEK, R. Características físicas e químicas de substratos para produção de Ilex paraguariensis St. Hil. Revista Árvore, Viçosa, MG, v. 31, n. 2, p. 209-220, 2007. 